\title{
Impact of tumor length on long-term survival of pT1 esophageal adenocarcinoma
}

\author{
William D. Bolton, MD, ${ }^{\text {a }}$ Wayne L. Hofstetter, MD, ${ }^{\text {a }}$ Ashleigh M. Francis, BS, ${ }^{\text {a }}$ Arlene M. Correa, MD, ${ }^{\mathrm{a}}$ \\ Jaffer A. Ajani, MD, ${ }^{\mathrm{b}}$ Manoop S. Bhutani, MD, ${ }^{\mathrm{c}}$ Jeremy Erasmus, MD, ${ }^{\mathrm{d}}$ Ritsuko Komaki, MD, ${ }^{\mathrm{e}}$ \\ Dipen M. Maru, MD, ${ }^{\mathrm{f}}$ Reza J. Mehran, MD, ${ }^{\mathrm{a}}$ David C. Rice, MD, ${ }^{\mathrm{a}}$ Jack A. Roth, MD, ${ }^{\mathrm{a}}$ \\ Ara A. Vaporciyan, MD, ${ }^{a}$ Garrett L. Walsh, MD, ${ }^{a}$ and Stephen G. Swisher, MD ${ }^{a}$
}

Introduction: The impact of esophageal tumor length on pT1 esophageal adenocarcinoma has not been well evaluated.

\begin{abstract}
Methods: Case histories of all patients $(n=133)$ undergoing esophageal resection from 1979 to 2007 with pT1 adenocarcinoma of the esophagus were reviewed. Univariate and multivariate analyses of esophageal tumor length and other standard prognostic factors were performed.

Results: Patients with early-stage pT1 esophageal adenocarcinoma with tumors less than $3 \mathrm{~cm}$ demonstrate decreased long-term survival ( 3 years: $>3 \mathrm{~cm}=46 \%$ vs $93 \% ; P<.001$ ) and higher risk of lymph node involvement (lymph node positive: $>3 \mathrm{~cm}=47 \% \mathrm{vs} 10 \% ; P<.001$ ). Multivariable analysis shows that esophageal tumor length $(>3 \mathrm{~cm}$ ) is an independent risk factor for survival in patients with pT1 early-stage esophageal cancer (hazard ratio: $4.8,95 \%$ confidence intervals: $1.4-16.5 ; P<.001$ ) even when controlled for submucosal involvement, lymph node involvement, and lymphatic/vascular invasion status. In combination with submucosal involvement, esophageal tumor length $(>3 \mathrm{~cm})$ identifies a high-risk population of pT1 esophageal adenocarcinoma (3 years: group 1 [0 risk factors] $=100 \%$, group $2[1$ risk factor $]=87 \%$, and group 3 [2 risk factors] $=33 \% ; P<.001$ ).

Conclusions: This study demonstrates that esophageal tumor length $(>3 \mathrm{~cm})$ is a risk factor for long-term survival and lymph node involvement in early-stage pT1 esophageal adenocarcinoma. Esophageal tumor length $(>3 \mathrm{~cm})$ in combination with submucosal involvement may help to identify a high-risk group of patients with pT1 esophageal adenocarcinoma.
\end{abstract}

In esophageal cancer the T classification for esophageal carcinoma is currently based solely on tumor depth. ${ }^{1}$ Several authors have found tumor length to be a significant factor in predicting survival for patients with esophageal cancer. ${ }^{2-6}$ We have also observed that tumor length $(>3 \mathrm{~cm})$ appears to be an important factor in patients with predominantly more advanced nonmetastatic esophageal cancer. ${ }^{7}$ The potential impact that tumor length $(>3 \mathrm{~cm})$ has on patients with earlier pT1 adenocarcinoma of the esophagus has not been well studied.

From the Departments of Thoracic and Cardiovascular Surgery, ${ }^{\mathrm{a}}$ Gastrointestina Medical Oncology, ${ }^{\mathrm{b}}$ Diagnostic Radiology, ${ }^{\mathrm{c}}$ Gastrointestinal Medicine and Nutrition, ${ }^{\mathrm{d}}$ Radiation Oncology, ${ }^{\mathrm{e}}$ and Pathology, ${ }^{\mathrm{f}}$ The University of Texas M. D. Anderson Cancer Center, Houston, Tex.

This work was supported by the Homer Flower Gene Therapy Research Fund, the Charles Rogers Gene Therapy Fund, the Flora \& Stuart Mason Lung Cancer Research Fund, the Charles B. Swank Memorial Fund for Esophageal Cancer Research, the George O. Sweeney Fund for Esophageal Cancer Research, the Phalan Thoracic Gene Therapy Fund, and the M. W. Elkins Endowed Fund for Thoracic Surgical Oncology.

Received for publication May 9, 2008; revisions received Jan 16, 2009; accepted for publication Feb 2, 2009; available ahead of print April 10, 2009.

Address for reprints: Stephen G. Swisher, MD, The University of Texas M. D. Anderson Cancer Center, Department of Thoracic and Cardiovascular Surgery, 1515 Holcombe Blvd, Box 445, Houston, TX 77030 (E-mail: sswisher@mdanderson.org).

J Thorac Cardiovasc Surg 2009;138:831-6

$0022-5223 / \$ 36.00$

Copyright (C) 2009 by The American Association for Thoracic Surgery

doi:10.1016/j.jtcvs.2009.02.003
In this study, we therefore evaluate the importance of our previously determined tumor length $(>3 \mathrm{~cm})$ in patients with pT1 adenocarcinoma of the esophagus to determine whether this factor is also able to help predict the risk of lymph node involvement and long-term survival in patients with earlier stage esophageal adenocarcinoma.

\section{METHODS AND PATIENTS Study Population}

Data were obtained from the prospectively collected esophageal database of the Department of Thoracic and Cardiovascular Surgery at the University of Texas M. D. Anderson Cancer Center (MDACC). The database was reviewed from 1979 to 2007 . A total of 1483 patients had surgical resection for esophageal cancer. All patients underwent surgical management without preoperative chemotherapy or radiation. Patients with histologic features other than adenocarcinoma $(n=480)$ were excluded. Patients with tumors having a T classification other than pT1 $(n=781)$ or patients who had chemotherapy or radiation therapy before surgery $(n=84)$ were excluded. Other exclusion criteria included patients who had an emergency, salvage, or redo operation or those who did not undergo a curative operation $(n=2)$. Those patients who died perioperatively $(n=3)$ were excluded so that we could evaluate only the long-term impact of tumor-related factors and not the short-term effect of perioperative death. Perioperative deaths were defined as death during admission or death within 30 days of surgery. There was no relationship with perioperative mortality and tumor length or submucosal involvement. This left our study population at 133 patients. The Institutional Review Board at The University of Texas MDACC approved this study. 


\section{Abbreviations and Acronyms \\ $\mathrm{CI}=$ confidence intervals \\ $\mathrm{CT}=$ computed tomography \\ HR = hazard ratio \\ LVI = lymphatic/vascular invasion \\ MDACC $=$ M. D. Anderson Cancer Center \\ PET = positron emission tomography}

\section{Acquisition of Data}

Preoperative staging was assessed by endoscopy, computed tomography (CT), positron emission tomography (PET), PET-CT scans, endoscopic ultrasound, fine needle aspirations, and staging laparoscopy as available for the time period. Patients underwent an Ivor Lewis esophagectomy, a transhiatal esophagectomy, a three-field esophagectomy, or a minimally invasive esophagectomy per discretion of the surgeon and patient desires. Pathologic staging of the tumor was performed using standard guidelines and the American Joint Commission for Cancer esophageal cancer staging system. ${ }^{1}$ Esophageal tumor length was determined by pathologic evaluation in all cases.

\section{Definition of Risk Factor Groups}

Patients were divided into two groups on the basis of tumor length: one group comprised patients with tumors greater than $3 \mathrm{~cm}$ in length and the second group comprised patients with tumors $3 \mathrm{~cm}$ in length or shorter. A cutoff value of $3 \mathrm{~cm}$ was used in this study because of our group's previous study in patients with more advanced tumors and an effort to determine whether this cutoff would also be applicable in earlier stage tumors. ${ }^{7}$

We also added esophageal tumor length to submucosal involvement, which is a previously recognized risk factor, ${ }^{8,9}$ to see whether we could identify a high-risk group of patients with pT1 esophageal adenocarcinoma. Patients with tumors $3 \mathrm{~cm}$ in length or less and with no submucosal involvement were classified as group 1. Patients with tumors that were either more than $3 \mathrm{~cm}$ in length or that had submucosal involvement, but not both, were classified as group 2. Patients with tumors that were both more than $3 \mathrm{~cm}$ in length and had submucosal involvement were classified as group 3 .

\section{Statistical Analysis}

The Kaplan-Meier method was used to estimate survival curves. The definition of survival was determined from the date of surgery and the last known follow-up or date of death. Perioperative deaths were excluded so that long-term survival owing to tumor-related factors and not short-term outcomes could be assessed. The Pearson $\chi^{2}$ and Fisher exact tests were used to analyze significance where appropriate. Univariable Cox proportional hazards regression model was used to examine the association between various prognostic predictors and survival (Table 1). Univariate factors with a $P$ value of $<.25$ and believed to be associated with cancer-related deaths were entered into a multivariable Cox proportional hazards regression model. Using the Wald stepwise selection with $P=.10$ as entry and removal probability, we obtained the final model for the data set. The statistical calculations were performed with the SPSS Software for Windows (version 15; SPSS, Inc, Chicago, Ill) and GraphPad Prism (version 5; Invitrogen, Carlsbad, Calif).

\section{RESULTS}

\section{Patient Characteristics}

The total number of patients in this analysis was 133 . The median follow-up was 42 months. Table 2 summarizes the patient demographics showing a predominantly white
TABLE 1. Cox regression analysis

\begin{tabular}{|c|c|c|c|c|}
\hline \multirow[b]{2}{*}{ Factor } & \multicolumn{4}{|c|}{ Univariate Cox regression } \\
\hline & $\mathbf{N}$ & $P$ value* & HR & $\mathbf{9 5} \%$ CI \\
\hline \multicolumn{5}{|l|}{ Tumor depth } \\
\hline No submucosa & 64 & & 1.00 & \\
\hline Submucosa involved & 69 & .005 & 4.19 & $1.55-11.33$ \\
\hline \multicolumn{5}{|l|}{ Tumor length } \\
\hline Continuous variable & 133 & $<.001$ & 1.51 & $1.22-1.87$ \\
\hline Tumor length & & $<.001$ & & \\
\hline 0-1 cm (reference) & 70 & & 1.00 & \\
\hline$>1-2 \mathrm{~cm}$ & 33 & .37 & 1.65 & $0.45-4.92$ \\
\hline$>2-3 \mathrm{~cm}$ & 15 & .20 & 2.43 & $0.65-9.50$ \\
\hline$>3 \mathrm{~cm}$ & 15 & .001 & 9.00 & $3.2-25.1$ \\
\hline \multicolumn{5}{|l|}{ Tumor length } \\
\hline$\leq 3 \mathrm{~cm}$ (reference) & 118 & & 1.00 & \\
\hline$>3 \mathrm{~cm}$ & 15 & $<.001$ & 6.69 & $2.81-15.89$ \\
\hline \multicolumn{5}{|l|}{ Nodal status } \\
\hline N0 (reference) & 114 & & 1.00 & \\
\hline N1 & 19 & .02 & 3.25 & $1.25-8.45$ \\
\hline \multicolumn{5}{|l|}{ LVI status $^{2}$} \\
\hline No (reference) & 102 & & 1.00 & \\
\hline Yes & 23 & .01 & 3.42 & $1.29-9.06$ \\
\hline \multicolumn{5}{|l|}{ Grade } \\
\hline $\begin{array}{c}\text { Well/moderately } \\
\text { differentiated } \\
\text { (reference) }\end{array}$ & 93 & & 1.00 & \\
\hline Poor/undifferentiated & 34 & .02 & 2.71 & $1.19-6.18$ \\
\hline \multicolumn{5}{|l|}{ Barrett esophagus } \\
\hline No (reference) & 12 & & 1.00 & \\
\hline Yes & 121 & .83 & 1.18 & $0.27-5.07$ \\
\hline
\end{tabular}

$(93 \%)$, male $(89 \%)$ population with the most common tumor location in the lower esophagus $(92 \%)$. The median age was 63 years. Table 3 summarizes the pathologic tumor factors demonstrating a similar number of patients with $(52 \%)$ and without submucosal involvement (48\%). Most patients were node negative $(86 \%)$ and did not have lymphatic/vascular invasion (LVI) on pathologic examination $(77 \%)$. There were 118 patients with a tumor length of 3 $\mathrm{cm}$ or less and 15 patients with tumors greater than $3 \mathrm{~cm}$ in length. The median tumor length was $1.34 \mathrm{~cm}$. The overall distribution of tumor length is demonstrated in Figure 1.

\section{Analysis by Tumor Length}

Survival was significantly improved in patients with shorter tumors when assessed in a continuous fashion $(P<$ .001 , hazard ratio $[\mathrm{HR}]=1.51$, confidence interval $[\mathrm{CI}]=$ $1.22-1.87)$. A cutoff value of $3 \mathrm{~cm}$ was used in this study in an effort to determine whether this cutoff would be applicable in pT1 esophageal adenocarcinoma as well as more advanced tumors. ${ }^{7}$ Initial exploratory analyses in patients with pT1 esophageal adenocarcinoma suggested that this cutoff might also be significant inasmuch as a significant decrease in long-term survival occurred when the tumors exceeded 
TABLE 2. Demographics

\begin{tabular}{lc}
\hline Demographics & No. $(\%)$ \\
\hline Patients & 133 \\
Gender & \\
$\quad$ Male & $118(89 \%)$ \\
Female & $15(11 \%)$ \\
Age, y (median, range) & $63(26-83)$ \\
Race & \\
$\quad$ White & $124(93 \%)$ \\
Hispanic & $8(6 \%)$ \\
African American & $1(1 \%)$ \\
Location & \\
Upper/middle & $10(8 \%)$ \\
Lower/GEJ & $123(92 \%)$ \\
Type of esophageal resection & \\
ILE & $57(43 \%)$ \\
THE & $63(47 \%)$ \\
Three field & $7(5 \%)$ \\
MIE & $6(5 \%)$ \\
pT1 subsets & \\
No submucosal involvement and $\leq 3 \mathrm{~cm}$ in length & $61(52 \%)$ \\
No submucosal involvement and $>3 \mathrm{~cm}$ in length & $3(2 \%)$ \\
Submucosal involvement and $\leq 3 \mathrm{~cm}$ in length & $57(48 \%)$ \\
Submucosal involvement and $>3 \mathrm{~cm}$ in length & $12(9 \%)$ \\
\hline GEJ, Gastroesophageal junction; $I L E$, Ivor Lewis esophagectomy; $T H E$, transhiatal \\
esophagectomy; $M I E$, minimally invasive esophgectomy. & \\
&
\end{tabular}

$3 \mathrm{~cm}$ in length (median survival: $<1 \mathrm{~cm}=175$ months, $1 \mathrm{~cm}$ to $<2 \mathrm{~cm}=166$ months, $2 \mathrm{~cm}$ to $<3 \mathrm{~cm}=97$ months, $>3$ $\mathrm{cm}=67$ months; $P<.001)$. Additionally, a categorical assessment of tumors that were $3 \mathrm{~cm}$ or less in length compared against patients with tumors greater than $3 \mathrm{~cm}$ (Table 4 and Figure 2) suggested that this cutoff identified a significant drop-off in long-term survival. The 3- and 5year survivals for patients with tumors $3 \mathrm{~cm}$ or less were $93 \%$ and $85 \%$, respectively, compared with 3 - and 5-year survivals for patients with tumors of more than $3 \mathrm{~cm}$ of $46 \%$ and $34 \%(P<.01)$. Lymph node involvement and LVI was also more likely in patients with tumors greater than $3 \mathrm{~cm}$ in length ( $47 \%$ and $54 \%$, respectively) versus patients with tumors $3 \mathrm{~cm}$ or less $(10 \%$ and $14 \%$, respectively) $(P<.01)$. Survival in patients without lymph node metastases was worse in patients with tumors greater than $3 \mathrm{~cm}(\mathrm{~N} 0$, $>3 \mathrm{~cm}$ median survival 30 months vs 204 months if N0, $\leq 3$ $\mathrm{cm} ; P<.01)$. There was also a trend to decreased survival in the subset of node-positive patients with larger tumors $(\mathrm{N} 1$, $>3 \mathrm{~cm}$ median survival not reached vs 21.3 months for N1, $\leq 3 \mathrm{~cm} ; P=.1)$. The small number of patients with intramucosal involvement ( 3 patients) and greater than $3 \mathrm{~cm}$ esophageal length makes more detailed analysis difficult with this small sample size.

Tumor length was also significantly associated with disease-free survival, with tumors less than $3 \mathrm{~cm}$ having a disease-free survival of 218 months versus 94 months for tumors greater than $3 \mathrm{~cm}(P<.001)$. Disease-free survival
TABLE 3. Pathologic features

\begin{tabular}{lc}
\hline Pathologic factor & No. $(\%)$ \\
\hline Tumor depth & \\
No submucosal involvement & $64(48 \%)$ \\
Submucosal involvement & $69(52 \%)$ \\
Tumor length & \\
$0-1 \mathrm{~cm}$ & $70(53 \%)$ \\
$>1-2 \mathrm{~cm}$ & $33(25 \%)$ \\
$>2-3 \mathrm{~cm}$ & $15(11 \%)$ \\
$>3 \mathrm{~cm}$ & $15(11 \%)$ \\
Nodal status & \\
N0 & $114(86 \%)$ \\
N1 & $19(14 \%)$ \\
LVI status & \\
No & $102(77 \%)$ \\
Yes & $23(17 \%)$ \\
Missing & $8(6 \%)$ \\
Grade & \\
Well/moderately differentiated & $93(70 \%)$ \\
Poor/undifferentiated & $34(26 \%)$ \\
Missing & $6(5 \%)$ \\
Barrett esophagus & \\
Yes & $121(91 \%)$ \\
No & $12(9 \%)$ \\
\hline
\end{tabular}

LVI, Lymphatic/vascular invasion.

also correlated with esophageal length when tumor length was evaluated as a continuous variable (HR 1.49 [1.211.84]; $P<.001)$ or with a categorical cutoff of $3 \mathrm{~cm}$ (HR 6.1, CI 2.6-14.3; $P<.001)$. The locoregional recurrence was more frequent in tumors greater than $3 \mathrm{~cm}(4 / 15 \mathrm{pa}-$ tients, $27 \%)$ than in those that were $3 \mathrm{~cm}$ or less $(2 / 118 \mathrm{pa}-$ tients, $2 \% ; P=.001)$. Distant recurrence was also more frequent in tumors greater than $3 \mathrm{~cm}(20 \%)$ than in those $3 \mathrm{~cm}$ or less $(5 / 118$ patients, $4 \% ; P<.05)$.

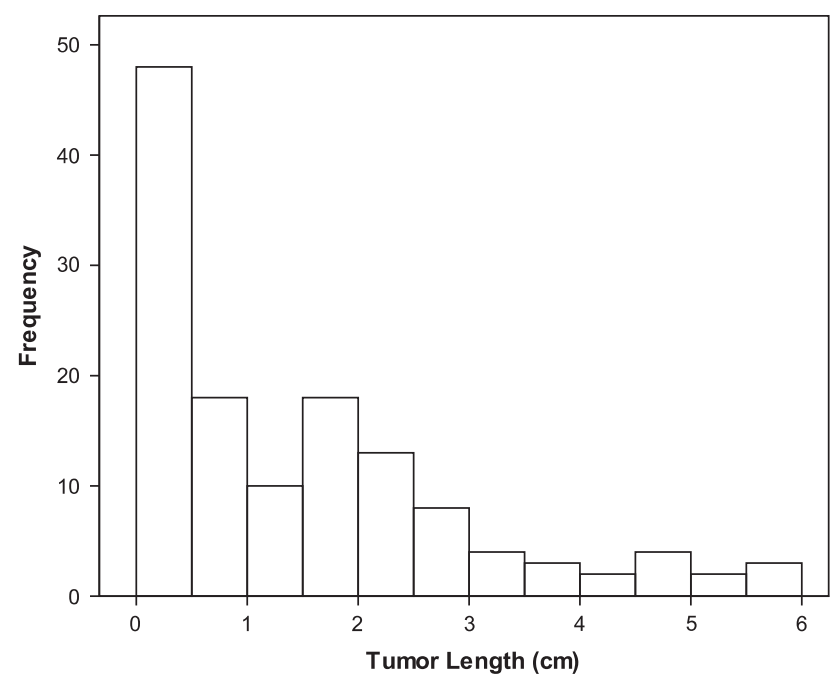

FIGURE 1. Histogram distribution of esophageal tumor lengths. 
TABLE 4. Outcome according to tumor depth, tumor length, and risk factor group

\begin{tabular}{|c|c|c|c|}
\hline & $\begin{array}{c}\text { Five-year } \\
\text { survival }\end{array}$ & $\begin{array}{c}\% \mathbf{L N} \\
\text { positive }\end{array}$ & $\begin{array}{r}\% \text { LVI } \\
\text { positive }\end{array}$ \\
\hline \multicolumn{4}{|l|}{ Tumor depth } \\
\hline No submucosa $(\mathrm{n}=64)$ & $90 \%$ & $5 \%$ & $7 \%$ \\
\hline Submucosa $(n=69)$ & $69 \% \ddagger$ & $23 \% \ddagger$ & $29 \% \ddagger$ \\
\hline \multicolumn{4}{|l|}{ Tumor length } \\
\hline$\leq 3 \mathrm{~cm}(\mathrm{n}=118)$ & $85 \%$ & $10 \%$ & $14 \%$ \\
\hline$>3 \mathrm{~cm}(\mathrm{n}=15)$ & $34 \% \ddagger$ & $47 \% \ddagger$ & $54 \% \ddagger$ \\
\hline \multicolumn{4}{|l|}{ pT1 subgroups* } \\
\hline Group 1 (reference) $(\mathrm{n}=61)$ & $90 \%$ & $3 \%$ & $7 \%$ \\
\hline Group $2(\mathrm{n}=60)$ & $81 \% \dagger$ & $18 \% \ddagger$ & $21 \% \ddagger$ \\
\hline Group $3(n=12)$ & $22 \% \ddagger$ & $50 \% \ddagger$ & $70 \% \ddagger$ \\
\hline
\end{tabular}

\section{Analysis by Tumor Depth}

As noted by other authors, tumor depth also correlated with long-term outcome in patients with pT1 disease. ${ }^{8,9}$ The 3- and 5-year survivals were significantly improved in patients without submucosal involvement $(100 \%$ and $90 \%$, respectively) compared with those with submucosal involvement $(77 \%$ and $69 \% ; P<.01$, Table 4 and Figure 3$)$. Patients with submucosal involvement were also significantly more likely to have positive lymph nodes $(23 \%$ vs $5 \%)$ and LVI ( $29 \%$ vs $7 \%)$ than were patients without submucosal involvement $(P<.01$ and $P<.01$, respectively). The combination of tumor length greater than $3 \mathrm{~cm}$ and submucosal involvement identified a higher risk group of pT1 patients than did submucosal involvement alone (5 years: $22 \%$ vs $69 \% ; P<.01)$.

\section{Analysis by Proposed Revised T Classification}

The disease was clinically staged with endoscopy (133 patients), endoscopic ultrasound (85 patients), CT scan (121 patients), and PET scan (58 patients). The clinical stage before resection was stage 0 (7 patients), stage I (78 patients), stage IIA/B (43 patients), stage III ( 2 patients), and incomplete stage ( 2 patients). All patients except 2 had R0 resections ( 2 positive proximal margins), and only 2 patients received adjuvant therapy. Assessment of outcome, when we added tumor length to submucosal involvement, demonstrated the potential relevance of our previously defined $3-\mathrm{cm}$ esophageal tumor length cutoff and submucosal involvement in pT1 esophageal adenocarcinoma (Table 4 and Figure 4). One of the limitations of this study is indeed the small sample size. As an example, the subset of patients with intramucosal tumors greater than $3 \mathrm{~cm}$ and lymph node metastases was too small to perform a meaningful analysis (3 patients). Additionally only 2 patients had intramucosal tumors that are greater than $3 \mathrm{~cm}$ and node-negative disease. These small numbers make determining the true variable

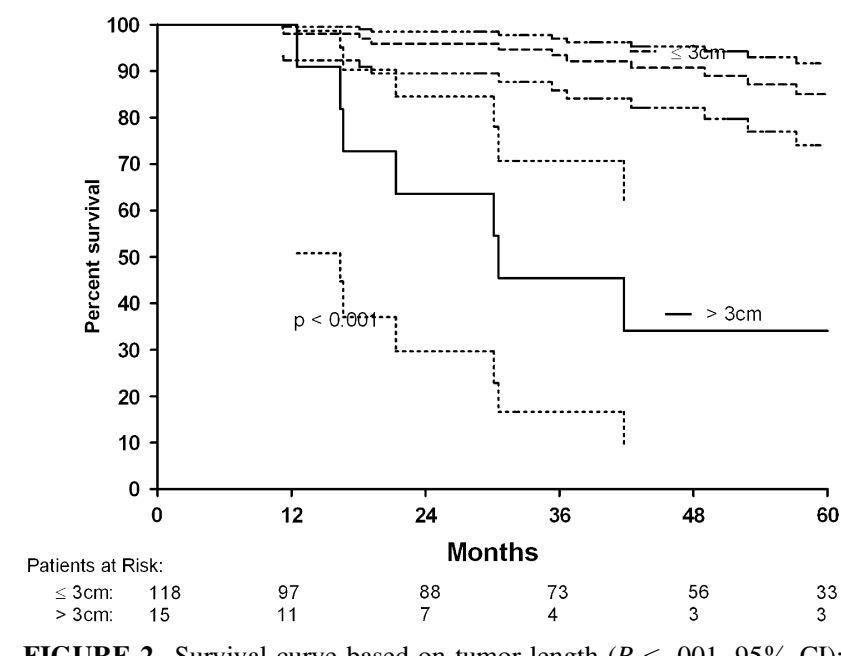

FIGURE 2. Survival curve based on tumor length $(P<.001,95 \% \mathrm{CI})$ : $\leq 3 \mathrm{~cm}, \mathrm{n}=118 ;>3 \mathrm{~cm}, \mathrm{n}=15 ; P<.001$.

responsible for decreased long-term survival difficult (ie, tumor length vs depth) and emphasize the fact that this study is only exploratory and will require a larger, prospective study in the future to validate and to confirm the proper cutoff point.

\section{Univariate and Multivariate Analysis}

Univariate analysis was performed by the Cox regression method (Table 1). We observed no survival difference when we looked at the type of surgical resection performed (ie, transhiatal esophagectomy vs Ivor Lewis esophagectomy and 3-field esophagectomy [HR: 0.48, 1.00, and 1.22, respectively; $P=.4]$ ), even when subsetted according to tumor length ( $>3 \mathrm{~cm}, P=.1 ; \leq 3 \mathrm{~cm}, P=.6$ ). The unadjusted hazard ratio for esophageal tumor length with a cutoff of $3 \mathrm{~cm}$ was 6.69 (CI 2.81-15.89; $P<.001$ ). The only



FIGURE 3. Survival curve based on tumor depth ( $95 \% \mathrm{CI})$ : no submucosal involvement, $\mathrm{n}=64 ;$ submucosal involvement, $\mathrm{n}=69 ; P=.002$. 


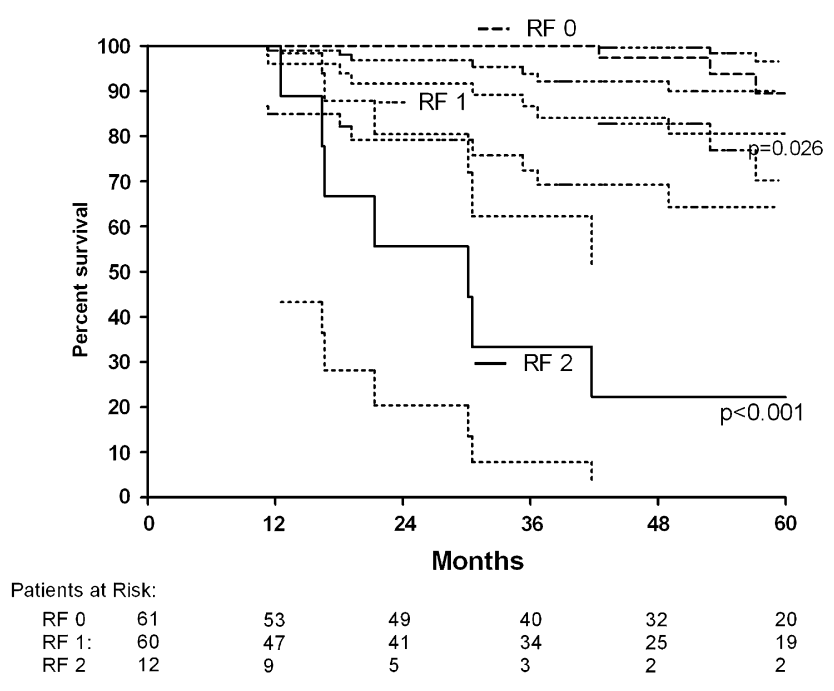

FIGURE 4. Survival based on number of risk factors in patients with pT1 esophageal adenocarcinoma ( $95 \% \mathrm{CI}): R F 0$, no submucosal involvement and tumor length $\leq 3 \mathrm{~cm}, \mathrm{n}=61 ; R F 1$, submucosal involvement or tumor length $>3 \mathrm{~cm}, \mathrm{n}=60 ; P=.026 ; R F 2$, submucosal involvement and tumor length $>3 \mathrm{~cm}, \mathrm{n}=12 ; P<.001$.

pathologic factor not significant on univariate analysis was the presence of Barrett dysplasia.

We then performed a multivariable Cox proportional hazard regression model of all variables from Table 4 with a $P$ value of .25 or less and esophageal length with a cutoff of 3 $\mathrm{cm}$ or multiple cutoff points, as noted in Table 4. According to the Wald stepwise selection with $P=.10$ as entry and removal probability, the final model for a $3-\mathrm{cm}$ cutoff $(>3 \mathrm{~cm}$, adjusted HR 5.5, CI 2.09-14.46; $P=.001)$ or multiple cutoff points was significant $(P=.007)$. The only other variable significant by this process was tumor depth (submucosal involvement: HR 3.17, CI 1.08-9.25; $P=.35$ ).

\section{DISCUSSION}

Several investigators have evaluated tumor length as a predictor of survival in patients with esophageal carcinoma during the past 10 years. ${ }^{4-6,10,11}$ One study, by Eloubeidi and associates $^{6}$ in 2002, based on data from the National Cancer Institute Surveillance Epidemiology End Results database, found that tumor length greater than $3 \mathrm{~cm}$ was associated with decreased overall survival when compared with shorter tumors. In this study, a significant portion of the patients $(43.8 \%)$ did not have tumor length recorded, and therefore it could not be used in the calculations. A consistent method of tumor length measurement was also not used in the study, so that it is difficult to make firm conclusions. A second study from Germany, by Bollschweiler and associates ${ }^{4}$ in 2006, examined the impact of tumor length on survival. They looked at tumors longer than $3 \mathrm{~cm}$ and found on univariate analysis that patients with tumors of $3 \mathrm{~cm}$ or less had a better 5-year survival than patients who had tumors that were longer than $3 \mathrm{~cm}$. On multivariate analysis, how- ever, they found that there was no difference in survival based on tumor length. A third study from Japan, by Tachibana and colleagues ${ }^{10}$ in 1999 , evaluated 129 patients with squamous cell carcinoma and found that tumor length was not an independent predictor for survival in patients with squamous cell carcinoma of the esophagus. Recently, Altorki and coworkers ${ }^{11}$ looked at patients with early (pT1) esophageal carcinoma and found that patients with longer tumors as well as patients with submucosal involvement had a decreased 5-year survival and were more likely to have multifocal disease. They concluded that patients with submucosal involvement were not good candidates for nonsurgical management because of potential lymph node involvement and decreased long-term survival.

Our group ${ }^{7}$ has previously demonstrated that esophageal tumor length is an important predictive factor in a group of patients with more advanced esophageal cancer. In this previous study, $3 \mathrm{~cm}$ was used as a cutoff point because it was the median size of the population and this was the size at which an asymptote occurred. In this current article, we attempted to determine whether this previously determined cutoff point $(3 \mathrm{~cm})$ was also applicable in earlier pT1 esophageal adenocarcinoma. We excluded all patients with neoadjuvant treatment to avoid treatment effects in the analysis. Using these criteria, we were able to show that tumor length greater than $3 \mathrm{~cm}$ is indeed a predictor of survival for patients with pT1 esophageal adenocarcinoma. The 5-year survival for patients with tumors greater than $3 \mathrm{~cm}$ was $34 \%$ compared with $85 \%$ for patients with tumors of $3 \mathrm{~cm}$ or less. We also found that patients with tumors greater than $3 \mathrm{~cm}$ were more likely to have positive lymph nodes and LVI in the pathologic specimens. Importantly, even when controlling for lymph node status and LVI, which are known to portend a bad prognosis, ${ }^{9,12-15}$ tumor length was still a predictor of survival in our patients. Limitations of this study include the fact that this is a small dataset at a single institution and validation of this prognostic factor will require a larger prospective data set from other institutions. Another limitation of this study is that $3 \mathrm{~cm}$ was selected as a cutoff from previous work by our group in more advanced tumors. ${ }^{7}$ Future studies may find that there is a more optimal cutoff point for earlier stage tumors and, as with patients who have lung cancer, there may indeed be several important esophageal length cutoff points.

We also examined our data to see whether the addition of tumor length to an established T1 prognostic factor (submucosal involvement) could identify a high-risk group of patients with pT1 esophageal adenocarcinoma. ${ }^{8,14}$ We found that when patients were stratified into new pT1 subgroups there was a significant difference in survival among patients in groups 1, 2, and 3 (Table 4). Patients with tumors of $3 \mathrm{~cm}$ or less and no submucosal involvement (group 1) had a 5year survival of $90 \%$, whereas patients in group 2 (tumors $>3 \mathrm{~cm}$ or submucosal involvement) had a 5-year survival 
of $81 \%$. Patients with both tumor length greater than $3 \mathrm{~cm}$ and submucosal involvement (group 3 ) had a 5-year survival of $22 \%$. Patients in group 3 were also at significantly higher risk of lymph node involvement, suggesting that patients in this group may not be ideal candidates for nonsurgical ablative or endoscopic mucosal resection techniques.

As previously mentioned, there are significant limitations within our study, and over-interpretation of the data should be avoided. First, this is a retrospective study that is limited by the data that were available for analysis at a single institution. The study population was only 133 patients, which leaves some groups small in the statistical analyses. We chose to use a cutoff point of $3 \mathrm{~cm}$ because of work in our prior study with predominantly more advanced tumors. ${ }^{7} \mathrm{Fu}$ ture studies may reveal that there are other cutoff points that are more applicable for early-stage tumors and later-stage tumors. This study simply demonstrated that the previous 3-cm cutoff was also predictive in pT1 esophageal adenocarcinoma. It is also important to recognize that the study population was limited to patients with adenocarcinoma and may not apply to patients with other types of esophageal carcinoma, such as squamous cell carcinoma.

In summary, this study should not be over-interpreted and will require validation in other larger data sets. This study should be viewed as an exploratory study that suggests that esophageal tumor length may be a predictor of long-term survival in patients with pT1 esophageal adenocarcinoma. In combination with submucosal involvement, esophageal tumor length $(>3 \mathrm{~cm})$ identifies a group of patients with pT1 disease who are at high risk for lymph node involvement and decreased long-term survival. Prospective studies need to be performed in the future to confirm the significance of esophageal tumor length in pT1 esophageal adenocarcinoma and its potential ability to identify high-risk patients for adjuvant therapy and more extensive lymphadenectomy.

\section{References}

1. AJCC cancer staging handbook/American Joint Committee on Cancer. 6th ed. Philadelphia: Lippincott-Raven; 2002. p. 3-8, 91-103.

2. Beahrs OH, Myers MH. American Joint Committee on Cancer. Manual for Staging of Cancer. 2nd ed. Philedelphia: JB Lippincott; 1983.

3. Sobin LH, Hermanek P, Hutter RVP. TNM classification of malignant tumors: a comparison between the new (1987) and the old editions. Cancer. 1988;61: 2310-4.

4. Bollschweiler E, Baldus SE, Schroder W, Schneider PM, Holscher AH. Staging of esophageal carcinoma: length of tumor and number of involved regional lymph nodes-are these independent prognostic factors? J Surg Oncol. 2006;94:355-63.

5. Griffiths EA, Brummell Z, Gorthi G, Prichard SA, Welch IM. Tumor length as a prognostic factor in esophageal malignancy: univariate and multivariate survival analyses. J Surg Oncol. 2006;93:258-67.

6. Eloubeidi MA, Desmond R, Arguedas MR, Reed CE, Wilcox CM. Prognostic factors for the survival of patients with esophageal carcinoma in the U.S. The importance of tumor length and lymph node status. Cancer. 2002;95:1434-43.

7. Yendamuri S, Swisher SG, Correa AM, Hofstetter W, Ajani JA, Francis A, et al. Esophageal tumor length is independently associated with long-term survival. Cancer. 2009; 115:508-16.

8. Rice TW, Blackstone EH, Adelstein DJ, Zuccaro G, Vargo JJ, Goldblum JR, et al. Role of clinically determined depth of tumor invasion in the treatment of esophageal carcinoma. J Thorac Cardiovasc Surg. 2003;125:1091-101.

9. Rizk N, Venkatraman E, Park B, Flores R, Bains MS, Rusch V. The prognostic importance of the number of involved lymph nodes in esophageal cancer: implications for revisions of the American Joint Committee on Cancer staging system. J Thorac Cardiovasc Surg. 2006;132:1374-81.

10. Tachibana M, Kinugasa S, Dhar DK, Kotoh T, Shibakita M, Ohno S, et al. Prognostic factors after extended esophagectomy for squamous cell carcinoma of the thoracic esophagus. J Surg Oncol. 1999;72:88-93.

11. Altorki NK, Lee PC, Liss Y, Meherally D, Korst RJ, Christos P, et al. Multifocal neoplasia and nodal metastases in T1 esophageal carcinoma: implications for endoscopic treatment. Ann Surg. 2008;247:434-9.

12. Gu Y, Swisher SG, Ajani JA, Correa AM, Hofstetter WL, Liao Z, et al. The number of lymph nodes with metastasis predicts survival in patients with esophageal or esophagogastric junction adenocarcimona who receive preoperative chemoradiation. Cancer. 2006;106:1017-25.

13. Cen P, Hofstetter WL, Correa AM, Wu TT, Lee JH, Ross WA, et al. Lymphovascular invasion as a tool to further subclassify T1b esophageal adenocarcinoma. Cancer. 2008;112:1020-7.

14. Liu L, Hofstetter WL, Rashid A, Swisher SG, Correa AM, Ajani JA, et al. Significance of the depth of tumor invasion and lymph node metastasis in superficially invasive (T1) esophageal adenocarcinoma. Am J Surg Pathol. 2005;29:1079-85.

15. Hofstetter W, Correa AM, Bekele N, Ajani JA, Phan A, Komaki RR, et al. Proposed modification of nodal status in AJCC esophageal cancer staging system. Ann Thorac Surg. 2007;84:365-75. 